\title{
The Social Treatment of Ex-Dropouts Reenrolled in Secondary School in South Africa
}

\author{
Byron A Brown ${ }^{1}$ \\ ${ }^{1}$ Faculty of Business and Leisure, University of Derby Programmes at BAC Campus, Gaborone, Botswana \\ Correspondence: Byron A Brown, Faculty of Business and Leisure, University of Derby Programmes at BAC \\ Campus, Fairgrounds Office Park, P/Bag 0319 Gaborone, Botswana. Tel: 267-7-230-5102. E-mail: \\ byronb@bac.ac.bw
}

$\begin{array}{lc}\text { Received: July 8, 2013 } & \text { Accepted: August 9, } 2013 \quad \text { Online Published: November 12, } 2013 \\ \text { doi:10.5539/jel.v2n4p60 } & \text { URL: http://dx.doi.org/10.5539/jel.v2n4p60 }\end{array}$

\begin{abstract}
Dropout recovery and return to school is an education access priority for government in countries in both the western and non-western worlds. In a qualitative investigation involving a sample of dropouts who had re-enrolled in secondary school in South Africa, this study explored antisocial aspects in their social experiences at school. The aim was to explore the social treatment of ex-dropout who rerolled in secondary school and discuss ways to help them reintegrate in the school community. The study revealed that the major antisocial aspects in dropout experience were prejudice and social hostility, expressed through experiences of social ostracism, isolation, categorisation and rejection. This was motivated by a matrix of intersecting modern and traditional forces. Relational and physical aggressions, which occurred in response to dropout out-group labelling and categorisation, were major factors in the social interactions. The evidence of hostility and reactions substantiated previous studies. The various implications of the findings for the school climate were highlighted. The study stressed that for dropouts to reintegrate, the entire school culture that condones social categorisation, relational or physical aggression against them, needs to be altered.
\end{abstract}

Keywords: social interaction, dropout reenrolment, Ostracism, aggression, secondary school, South Africa

\section{Introduction}

Dropout recovery and return to school is an education access priority for government in countries in both the western and non-western worlds. In Africa for example, the number of school-age children enrolment in secondary school has increased over the past decade (UNESCO, 2010), but school attendance has been marked by systemic weaknesses. Grade repetition and drop out are examples of such weaknesses (Brown, 2010). The majority of the world's dropouts can be found in the non-western world. Whereas in the OECD countries, almost 100 percent of the students enrol in secondary education, and whereas almost 80 percent of them go on to complete their schooling, the situation in Africa and Latin America is different. In these regions, about 50 percent of the students enrol in secondary school; of this number, less than a third complete secondary education (Carlson, 2012).

The cohort of dropouts globally is characterised by both temporary and permanent leavers. In the non-western world, the dropouts who return to secondary school are those who quit school temporarily. In countries such as South Africa, these re-enrolled ex-dropouts have had little opportunity to be heard by school councillors, psychologists and educators because either the support service is non-existent or there is a staff shortage to respond adequately to the demand for the service (Raymond, 2008). Reintegration is complex. When ex-dropouts return to school, they join a school community in which teaching and learning continued, despite their absence. As ex-dropouts, they are required to catch up on what they missed out on while they had been out of school. Many ex-dropouts may find it challenging to reintegrate in the school community - that is, to return to learning/teaching life in the social space at school. Scholars such as Brown (2012) and Maharaj, Kaufman, and Richter (2000) reported that it is not uncommon that ex-dropouts are given social labels. Yet the extent to which students are ostracised or treated antisocially in school in South Africa, where dropout incidence are relatively high, especially at the Grade 9 level (Brown, 2010; Brown, 2012) has been given little attention in research.

By contrast, most of the attention has been given in research to issues such as dropping out trends and determinants (Rumberger \& Lamb, 1998), dropout reenrolment hindrance and enablers (Berliner, Barrat, Fong \& Shirk, 2008; Bushnik, Barr-Telford \& Bussière, 2004), and the return-to-school, by gender (Raymond, 2008) of dropouts. 
These areas have been studied extensively. Variations in ex-dropout adjustment to the social environment at school are downplayed in the drop out literature.

The present study explored the social treatment of dropout (i.e., constructive or antisocial reactions) who returned to secondary school and discuss ways to help these students reintegrate in the school community. Presumably, social experiences are shaped in socio- cultural and economic systems as well as by intrinsic personality traits. These ideas eventually become differentiated and coalesce into what De Wet (2007) calls a sense of "in-group and out-group" identity. In-group /out-group binaries have relevance in this study. It can reflect how dropouts might be perceived and treated. The study was limited to the social treatment of dropout because, from a practitioner's point of view, being aware of these conditions can allow the identification of problem areas to dropout reintegration, and possible steps to take for change. Accordingly, being aware of the social treatment of the dropouts can shed light on possible areas for improvement at a school policy level. Since it is impossible to pay constant attention to individual dropout cases and circumstances at school, antisocial treatments might be minimised or avoided if the perpetrators can be confronted and made aware of their roles.

\subsection{Social Treatment}

The decision to return to school is a big personal decision for ex-dropouts. Staying out of school would have had detrimental economic and personal costs for the individual. Bridgeland, Dilulion and Morison (2006) found that a dropout who fails to complete school is much more likely than their mates who completed to be unemployed, living in poverty conditions, be in prisoned, getting government living assistance, and has children who drop out from school themselves. However, the decision to return to school puts ex-dropouts in a position of strain. At school, ex-dropouts are much more likely than other students to spend more time trying to catch up in the school curriculum. Depending on the duration of the time spent out of school, ex-dropouts are much more likely than other students to be older and more mature in class. The maturity level can lead the ex-dropouts to develop feelings of being outliers, or for others to treat them as outliers, in class (Briffa, 2010).

When ex-dropouts return to school, they re-join a school environment which is social by nature. The reaction towards the ex-dropouts may be pleasant and welcoming, or it may be hostile. Hostile social treatment may manifest in various forms, including stereotyping, prejudice, discrimination, scapegoating, rejection, and isolation (Briffa, 2010). The reception that an ex-dropout receives at school has a great influence on the sense of community that he/she develops - that is, his/her feelings of belonging to the school community (Furman, 2002). Stronger feeling of belonging is associated with pleasant and welcoming treatments.

The mere fact that an ex-dropout re-joins the school community does not necessarily mean that he/she is accepted by all his/her peers. Early scholars such as Tajfel (1970) advised that a community is not necessarily homogenous, because the community may be polarised by a variety of social ills that result from prejudices. Polarization of a social community leads to the formation of cleeks, which Tajfel (1970) and others (Briffa, 2010; De Wit, 2007) referred to as 'in-groups' and 'out-groups'. Various characteristics found in previous studies on dropouts may influence how the dropouts may be perceived in the school community. For instance, the literature on dropouts asserts that dropouts are individuals with a history of behavioural, attitudinal, school, and/or life event problems such as academic failure; disinterest in school; and delinquency. These problems may also include life event challenges such as poor health, pregnancy, or having to care for ill family member (Brown, 2010; 2012; Bridgeland et al, 2006; Reyna, 2011). These views of dropouts can influence how they are treated when they return to school.

It is not uncommon within the African context to find that ex-dropouts are treated in ways associated to the cause of dropping out of school (Reyna, 2011). When a student drops out of school due to financial constraints, for example, the child is likely to be viewed by his/her peers as poor and living in poverty conditions. Valorisation of such social label may lead to prejudice towards the ex-dropout. The social label ascribed to the individual does not necessarily disappear when the individual returns to school. In some culture, Brown (2005) asserts that many people living in poverty are told that they are '...no-good, inadequate, dirty, incompetent and stupid', so they may (or should) expect failure of themselves, just as the world expects it of them (Ross \& Roberts in Brown, 2005:396). In South Africa, wealth suggests prestige while poverty reflects a sorry condition of a person's life. These commentaries do have the potential to impact profoundly on the self-esteem of a learner who drops out of school and return later.

The return of ex-dropouts to a school community creates the existence of another group, relative to those students who never dropped out. Tajfel (1970) and others (e.g., Brewer, 1997; Goldstein, Young \& Boyd, 2008) have argued that the mere perception of the existence of another group can itself produce discrimination. To De Wit (2007), discrimination is a behavioural expression of prejudice. As social practice, both prejudice and 
discrimination are interlinked. Prejudice is an evoked response. Briffa (2010) found that prejudice is an attitude (usually negative) toward the 'other', purely on the basis of membership to the 'other group'. Sentiments of 'in-group' and 'out-group' may develop in a school community with relative number of ex-dropouts and other students who never dropped out. Studies have yet to explore whether the above does or does not occur with regards to ex-dropouts in the South African secondary school context.

\subsection{The Context of Ex-Dropout Reenrolment in South Africa}

Who is a dropout has always been a contested issue. This is largely because there has been no agreement on what should qualify as the out-of-school time duration, or the circumstances that led to the disruption in schooling. Different countries have different requirements. In South Africa, dropouts are individuals whose education has been disrupted, at least temporarily (for one month) or permanently (never to return). The disruption is caused not by institutionally imposed sanctions but rather by personal circumstances. Outside of this, the absence is disregarded as a drop out incident. It means therefore that cases of student suspension or expulsion are excluded from the drop out category. This distinction helps with clarifying decisions about who qualifies, or not, as ex-dropout participants.

The return of ex-dropouts to school in South Africa is part of effort to expand education access and redress apartheid era inequalities. While incidence of student drop out is high, with approximately 551,000 students estimated to drop out of school before Grade 12 each year (Kraak in Brown, 2010: 10), South Africa has made deliberate efforts to re-admit ex-dropouts (Motala et al, 2007). Unlike in many other country globally, in South Africa, there is a policy in place since 1996, which allows girls who dropped out of school due to pregnancy related reasons to return to school after giving birth, if these young mothers can manage to do so logistically and financially (Grant \& Hallman, 2006). This policy has been informally upheld by school principals even prior to 1996. Students who dropped out of school for reasons other than pregnancy, such as poor health, financial distress, and/or violence, are also able to return to secondary school to complete their education. Successful reintegration of ex-dropouts is a key priority.

In South Africa, incidence of drop out is relative high throughout the secondary school cycle. In secondary schools, drop out and reenrolment are most common at Grades 8, 9, 10 and 11 (Brown, 2010; Motala et al, 2007). As a result, it is quite common to find classes at different Grade levels with high number of ex-dropouts. In 2011/12, the annual school monitoring report revealed that in populated provinces such as Gauteng, Kwa Zulu Natal, Eastern Cape, as much as five percent of the student enrolment in 8, 9, 10 and 11 were ex-dropouts (ASMR, 2012). Furthermore, demographically, both male and female students make up the pool of ex-dropouts in secondary schools, with schools serving the historically disadvantaged black communities experiencing the highest incidents of drop out and re-enrolment attempts (ASMR, 2012; Grant \& Hallman, 2006).

Evidently, the presence of ex-dropouts in the secondary school environment is a reality that teachers, principals and peers have to face. The assumption among education stakeholders has always been that ex-dropouts are able to reintegrate with relative ease back into school and continue as normal with their learning. The literature on peer interpersonal relationship and social labelling hints that reintegration may not be as we initially thought. The quality of the social treatment that ex-dropouts experience has broader implications for not just how they learn but also how they adjust as individuals. Consequently, the social treatment that they experience cannot be downplayed. This study therefore investigated:

- The social treatments that ex-dropout experience from peers and teachers in secondary schools;

- Strategies which ex-dropouts perceived may assist them to successfully reintegrate into the school community.

\section{Methodology}

The study utilized an exploratory, qualitative approach because such approach has been shown in the past to be a useful way to study any sensitive opinions, attitudes, preferences, and behaviours related to constructive or antisocial issues, particularly when the opinions might be reflections of larger underlying attitudinal constructs. The social identity theory of intergroup relations informed this study. The social identity theory looks at the categorisation of social groups and considers group membership and competition a source of intergroup conflict and discrimination (Knippenberg, 2002). In other words, group membership creates in-group/self-categorisation and enhancement in ways that favour the in-group, at the expense of the out-group (Knippenberg, 2002). The Tajfel and Turner (1986) model of social identity theory exemplifies this approach. Having a particular social identity means being at one with a certain group, being like others in the group, seeing things from the group's perspective, and the consequences thereof (Tajfel \& Turner, 1986). The social aspects 
that dropouts experienced at school can provide a sense of whether or not they are categorised and whether they experienced any aspect of prejudice against them.

\subsection{Sample and Method}

The study involved a sample of eight ex-dropouts who re-enrolled at school. The sample comprised five females and three males were all Black South Africa mainly because of the schools (previous disadvantaged schools) selected, conveniently. Sample was selected from Grade 9, 10 and 11 Band. The convenience sampling method is highly valid and commonly used in the education field for data collection (Brown, 2010; Grant \& Hallman, 2006; Motala et al, 2007). The average age of these participants was 17. They had been out of school for periods ranging from 6 to 20 months. The anonymity of all the participants was assured by having them responding in the interview without declaring their personal information. The use of coded themes, and pseudonyms in reporting the findings contributed to improving confidentiality.

Data was collected through personal interviews, which were conducted face-to-face. These were in-depth, but the interview schedule was semi-structured. Interviews were tape recorded to ensure adequate verbatim accounts. All interviews were tape-recorded and transcribed verbatim, with one question kick-started the process: "Tell me about your social experiences with teachers/peers at school since re-enrolling" Probing questions followed; however, the process involved not just probing but also reflecting (e.g. "Could you tell me more about..."). In this way, the contents of each interview were determined by the participants. Data analysis was thematic, involving identifying recurrent themes (Corbin \& Strauss, 1990), linked to the objectives investigated. The findings are presented and discussed below.

\section{Findings and Discussion}

The social experience of the participants was diverse and complex. The dropouts re-joined school but their experience was marked by social hostility. The social hostility includes ostracism and isolation behaviours.

\subsection{Experience of Ostracism and Isolation}

According to the interviews, hostility was expressed largely in experiences of ostracism and isolation. As discussed below, the motivation for ostracising the dropouts was complex, but appears mainly related to the factors that pushed these individuals out of school. In particular, the study identified 'life events' such as HIV/AIDS related issues, delinquency, and family tragedy as conditions for increasing the likelihood of anti-sociality towards the dropouts who re-joined the school community. These experiences appear to lower their self-esteem and impact on their emotions. This point was well captured in the sentiments of one participant:

Some of them [the learners] gave me a tough time. They saw me as HIV infected because I was taking care of [my] sick sister who had HIV/AIDS. They do not want to socialise with me because they thought I am infected. I felt sad and angry... It made me furious... they [learners] diagnosed me without testing me... they know nothing about the pain I felt watching AIDS destroy my sister. They don't know that I am not infected but affected. [Mavuso]

In this case, reenrolment resulted in clear discrimination. To be discriminated against is to be categorised, ignored and excluded. However, the motivation to discriminate appears to differ. For Mavuso above, it was a prejudicial assumption. But for others, like Mmeli, it was academic weakness; he noted: 'I have no friends; nobody wants to be my friend in class... my school is an unfriendly environment; they [learners] ignored me as if I did not exist.... they chased me away... they think am useless for the reason that I am weak academically.... it makes me sad' [Mmeli]. In addition, Thembu experienced family tragedy and it motivated prejudicial behaviour against him:

They [learners] teased and stigmatised me because my father murdered my mother. They joked about the death of my mother... and called me "son of a murderer". School-life is hard now... I'm punished because of my father's sins. They [learners] don't want me to be in their class... I don't take part in sport... they don't want to play with me... I'm neglected. They say bad things about my family. [Thembu]

These examples are typical of the manner in which antisocial behaviour emerges in social interactions with 're-enrolled dropouts' in the school community. In these examples, prejudice is a result of group interaction and group membership, rather than group competition. Thus, although the dropouts re-enrolled at school, and posed no obvious threat to others, they were ostracized. Exclusion and social labelling are evidence of relational aggression (Briffa, 2010). Ostracism breaks down attachment. For the ex-dropouts, the attachment to colleagues seemed severed. This was illustrated by the hate, neglect, ridicule and/or isolation that characterised Thembu's, and others like him, experience. 
The social categorization and labelling of the 're-enrolled dropouts' are illustrations of antisocial habits. To understand these findings, it is helpful to make comparison with previous research into the origin of prejudice in intergroup interactions. Social identity theory (see Tajfel, 1970) explains that individuals isolate others to out-group when out-group members decrease their self-esteem. Social identity is the individual's self-concept derived from perceived membership of social groups (Hogg \& Vaughan, 2002). In other words, it is an individual-based perception of what defines the "us" associated with internalized group membership.

Previous research on social identity asserts that categorisation is an act of, and a precursor to, discrimination (Bodenhausen \& Peery, 2009) and is intended to separate. Thus, one outcome of categorisation is the formation of in-groups and out-groups (Tajfel, 1970). Ostracism is an indication that the 're-enrolled dropouts' were categorised and relegated to an out-group status.

The motive to relegate the re-enrolled dropouts to an out-group status may be related to multiple factors. On the one hand, fear of the dropouts, and on the other, a quest by other students to safeguard their self-esteem, given the stigma associated with some dropouts may have contributed to the categorisation. Their categorisation may also be driven by particular motives that were socially constructed and historically located within a matrix of intersecting postmodern and traditional factors. For instance, the fear of contracting HIV from someone who merely cared for an HIV/AIDS victim is connected to a misconception in many parts of Africa, South Africa included, which suggests that a person can catch the HIV virus by merely interacting with an HIV/AIDS victim (Kachieng, 2004). Likewise, social labels such as the 'son-of-a-murderer', carries extremely negative connotations in traditional African society as the son is viewed as deserving the same punishment as the father (Chiamaka, 2010).

Thus, the withdrawal of these re-enrolled dropouts and from the others such as Mmeli who confessed to being academically weak was perhaps a strategy to protect self-esteem, on the one hand, and to fulfil implicit traditional expectations, on the other. Consistent with Brewer's (1979) optimal distinctiveness model of social identity, social discrimination was motivated, not by competition or conflict, but solely by a quest to see the re-enrolled dropouts as separate (i.e., ingroup preference) in the absence of any negative affect or hostile intent toward them (re-enrolled dropouts). However, there was a reaction to the exclusion.

\subsection{Rejection of the Negative Evaluation}

From the interview data, we can see that the dropouts acted in response to the outgroup accentuation experienced when they returned to school. Their reaction was a rejection of the negative evaluation ascribed. The more exposed they became to acts of ostracism and isolation, the more steadfast and ardent the re-enrolled dropouts were to repel the negative treatment. For example, Zanoxolo and Nambita lamented, respectively:

I was in a gang and used to rob people. I think they [other students] treated me different because they are afraid of me. I am bossy and I felt nothing... I was abusive [to them] silently but I didn't care since they labelled me. [Zanoxolo]

Nambita was equally forthright:

I quitted school due to my pregnancy but when I came back, I had to be bossy to them [other students] because they had a way of 'looking down' on you. My teachers avoided me because of my behaviour... they know I would beat them up. [Nambita]

There is clear aggression in these responses, though physical - as reflected in the bullying and threatening of others. Aggression has been defined as 'a category of behaviour that causes or threatens harm to others' (Briffa, 2010 , p. 19), or that 'increases the status of the aggressor' (Hawley \& Vaughn, 2003). In other words, the re-enrolled dropouts rejected the out-group identity and treatment, by virtue perhaps of the inherent harm that it posed. This action shifts these individuals from victims to perpetrators in the intergroup confrontation. Thus, a key antisocial aspect in the experience of re-enrolled dropouts who rejected the out-group identity in the school community is calculated aggression, encompassing a variety of behaviours, including bullying.

Though physical aggression occurred, it was not the only form of reaction to the in-group negative bias. According to the interviews, there were also instances when relational aggression was adopted. Relational aggression involved self-isolation. When Thelma observed the manner in which she was treated by her peers in the school community, she deliberately detached herself from them. She noted:

I isolated myself from them [other students]...they think that I see myself as a better person than they are...they see me as the person who knows everything... when I try to help them with class work, they don't accept my 
assistance, and I am unable to ask them for assistance because they think that I'm just 'testing' their knowledge. [Thelma]

In each of the cases, it appears that the aggressive behaviour did not reflect discipline problems, or disengagement from school but rather a reaction to an immediate serious stressor. To be 'looked down upon' or be 'treated differently' was to be micrified and viewed as the other. In the end, the outcome was provocation. Thus, in terms of out-group reactions to in-group bias, the above findings complement previous research into the intergroup confrontation process (e.g., Dasgupta et al 2009; Bodenhausen \& Peery, 2009). Dasgupta et al (2009) argue that intergroup aggression is a by-product of in-group bias whereby challenges and threats to out-group beliefs/values provoke aggression towards the in-group. A key lesson is that experience in interacting with students who never dropped out of school helped returnee dropouts to identify socially discomforting behaviours that pose a challenge or threat to their self-esteem, and thus, to adapt in the school context. The decision to face up to the sources of the threat may be sensible, given that, as Cant, Llop and Field (2006) maintain, the best way to prevent anyone from negatively affecting one's self esteem is to confront them to refute their position.

In the quotes from the data, the responses to the in-group negative bias revealed two different approaches, expressed in simple words: "I isolated myself" versus "I was abusive". These two approaches followed gender cleavage. Whereas the self-isolation was reported by females, direct aggression was reported by males. In other words, Thelma's response to the in-group negative bias was in a different form from the responses of the others. While it may be a case of socially cultured and experienced individuals consciously analysed a situation, and subsequently chose the appropriate behaviour to make the best out of the interaction, the gender pattern in the response is in accordance with previous research into aggression. These studies have shown that girls are more likely than boys to use 'relational aggression', i.e., verbal and indirect aggression, such as, isolation, alienation, ostracism, character defamation and gossip (Bettencourt, Talley, Benjamin \& Valentine, 2006; Keenan \& Shaw, 1997). In addition, boys are more likely than girls to engage in both direct aggressive and antisocial behaviour (Keenan \& Shaw, 1997; Lahey, Schwab-Stone, Goodman, Rathouz, Miller, Canino, Bird, Jensen \& Waldman, 1998; Coie \& Dodge, 1998). Thus, a key lesson that can be learnt from the findings is that the reaction of re-enrolled dropouts of different gender to antisocial tendencies directed at them by virtue of being perceived as out-groups may take different forms.

\section{Further Discussion: Implications of Ostracism and Aggression for Dropout Reintegration}

The findings of the study illustrate that intergroup interaction between the re-enrolled dropouts and other students, categorised as in-group and out-group, was marked by tension. Consistent with social psychological theories (Hogg \& Vaughan, 2002), group membership and group interaction were sufficient to motivate acts of hostility, expressed in terms of ostracism, isolation, and social labelling. The prejudicial behaviour against the returnee dropouts motivated counter reactions, expressed in different forms of aggression in the school community. These antisocial aspects have resulted in re-enrolled dropouts being categorized as controversial in socio-metric status.

Based on the evidence above, this study has revealed two conditions in the intergroup interaction that have wider long term implications for dropout reintegration into the school community. First, the condition of social categorisation (e.g., as in-group vs. out-group; perpetrators vs. victims of ostracism/isolation); and secondly, the condition of social and relational aggression: expressed in terms of social labelling, name calling, ostracism, isolation, and bullying.

\subsection{Social Categorisation and Dropout Reintegration}

The effects of social categorisation and identification are pervasive and powerful. Social psychologists such as Brewer have reported that while humanity often undertakes social categorisation as a necessity, it can lead when its intention is negative - to a range of biases toward corresponding out-groups (Brewer, 1997). The indication in this study that the re-enrolled dropouts have been labelled, teased and ostracised suggests that their social categorisation had vicious intent. Since initial differentiations, however arbitrary, beget further social differentiation (Brewer, 1997), the danger is that, without some deliberate effort to breakdown the segmentation experienced, social differentiation against the re-enrolled dropout could persist unabated. If this is the case, this has important implications for the contents of interventions training. For example, intervention can no longer focus on cooperation, but will now have to include social skills training, and on finding the ideal social 'niche' for the re-enrolled dropouts. Both the perpetrators and the victims must be targeted to learn how to interact in positive ways. 
The fact that the re-enrolled dropouts have been cast as out-group suggests that they may have been both highly liked (probably by fellow out-group friends) and highly disliked (probably by in-group perpetrators) by their schoolmates. While social structure and individual psychology converge to make feelings of like or dislike an inevitable feature of social life, in a school context the situation is often different. Sometimes attitudes of dislike are short-lived, and at other times are transitory. Social psychologists are of the view that in such instances, the consequences on social development are minimal (McLeod, 2008). However, because social development is honed in interaction with others overtime (Brown, 2010), long-term exposure to rejection, neglect, isolation or being disliked has lifelong consequences, including deficits in social development - poor self-esteem, social withdrawal - and dislike of school (Hogg \& Vaughan, 2002). The evidence in this study of a participant, who, under the stress of antisocial relations at school, commented, “...I hate to see even the [school] buildings, let alone the people in them" [Mmeli], appears to illustrate the effect of such consequence.

Years of research into school climates suggests that students strive best in a school context that is defined by a sense of community, which is defined as the feeling of belonging in a group as a whole (Pooley, Breen, Pike, Cohen \& Drew, 2008). For the re-enrolled dropouts, social categorisation is anti-reintegration into the school community. The maintenance of social boundaries mediates opportunities for cooperation, imitation, interdependence or even mild positivity.

Furthermore, prolonged maintenance of social cleavages provides fertile ground for anti-community building behaviours such as indifference, disdain, or hatred. Since students spend a considerable amount of time at school, belonging is considered to be a precursor of a stable school experience (Erktin, Okcabol \& Ural, 2010). Although the sense of belonging is linked to, inter alia, respect for teachers, participation, academic success, and liking school (Furman, 2002), this research suggests that experience of ostracism and the feelings of isolation meant that the re-enrolled dropouts did not feel a sense of belonging in the school community. Students who feel isolated are more likely to fail (Beck \& Malley, 1998), which is disturbing because previous research has shown that academic failure is a major cause of drop out (Brown, 2010; 2012; Chuang, 1997; Erktin et al, 2010). Unless the situation of social segmentation is reversed, and a strong sense of community is actively cultivated and supported, there is a risk that the re-enrolled dropouts could be pushed out and become victims of repeat drop out.

School authorities need to take a greater role in reintegrating re-enrolled dropouts in the school community. Merely affixing their names to the enrolment list is insufficient because dropouts-who-returned are unlike other students. The findings of this study clearly show some of the experiences that these individuals go through upon returning to school. The social categorisation of those acknowledged as "re-enrolled dropouts", and those that fall outside that boundary, by implication stereotyped the returnee dropouts. This is because social categorisation goes hand in hand with the stereotyping process (Bodenhausen \& Peery, 2009). A stereotype is "... fixed, over generalised belief about a particular group or class of people" (McLeod, 2008, p. 1). The perception that re-enrolled dropouts are a failure was a salient thread that tied them together. As one participant in this study noted, "....they [other students] all belief we are failures" [Mmeli]. Perception that dropouts are delinquents and time-wasters is common in South African literature and is echoed in homes and on the street (Brown, 2010; 2012). One of the roles that school offices need to take in reintegrating dropouts who have returned to school is to implement measures to alleviate stereotypic tendencies and attitudes.

\subsection{Relational Aggression and Dropout Reintegration}

In addition to the influence that social categorisation has on dropouts, the case study data in this research also highlighted relational aggression as a key force that further influenced both the wider school climate and dropout reintegration. Relational aggression was a major factor in the social categorisation of re-enrolled dropouts. These behaviours were of three distinct categories: social alienation/ostracism (i.e., giving peers silent treatment), rejection (i.e., telling rumours and ascribing social labels), and social exclusion (i.e., excluding peers from social or play groups). These findings provide some support for the social identity theory of negative reciprocity (Tajfel, 1982; Tajfel \& Turner, 1986), and for the optimal distinctiveness theory of the need for inclusion in a larger social collective (Brewer, 1991). As dropouts returned to school, their drive for inclusion within the school community aroused but appeared frustrated by behaviours of differentiation from other schoolmates.

Unsupported, dropouts cannot reintegrate into a school community in which they are either victims or perpetrators of relational aggression. One of the main reasons is that relational aggression is distressing and harmful for both the victims and the perpetrators (Stejskal, 2010). Although no specific test of association between relationally aggressive behaviours and maladjustments was done in this study, many dropouts reported feelings of hurt and distress as a result of their experience of being ostracised, neglected and ridiculed. 
Many social and psychological problems have been attributed in previous studies to relational aggression and victimization, particularly among females (Borgia \& Myers, 2010; Keith \& Martin, 2005; Sullivan, 2006). Consequently, teachers and school principals should be very concerned about the occurrence of relational aggression involving dropouts and other students (who fall outside that category) because studies in the peer context have revealed that relational aggression interferes with key developmental tasks such as forming and maintaining intimate, close relationships with peers (Borgia \& Myers, 2010; Crick, Casas, \& Nelson, 2002). Victims of relational aggression are more likely to experience social difficulties, including being depressed, lonely, anxious, and socially isolated from their peers (Borgia \& Myers, 2010; Keith \& Martin, 2005; Sullivan, 2006). Other forms of maladjustment - such as internalizing and externalizing problems: e.g., increased delinquency, drugs and alcohol use - are also elevated among victims and perpetrators of relational aggression (Stejskal, 2010; Sullivan, 2006). Thus, the implication is that if relational aggression among the students is not contained, it stands to sabotage dropout reintegration into the school community.

On a related note, teachers and school principals should be quite concerned about the occurrence of relational aggression (and in some cases physical aggression) in the school community because it can impact the broader school climate. It is shown in previous research on school violence that in schools with higher levels of relational aggression, students feel less safe (Goldstein, Young, \& Boyd, 2008), and, by virtue of social learning, students are more likely to use relationally aggressive strategies to solve problems in classrooms with higher overall levels of relationally aggressive behaviours (Kuppens, Grietens, Onghena, Michiels, \& Subramanian, 2008). The relational aggression reported in this study can lead to physical aggression (physical aggression has already been reported) within the school context. Thus, the intergroup hostility between these students may be a source of school violence.

Nevertheless, previous research highlighted key challenges with regards to detecting relational aggression, which teachers and school administers cannot ignore. A challenge teachers and school administrators have is that they may not directly witness acts of relational aggression, given the covert nature of such aggression; they also have a challenge in determining their point of intervention given the delicate nature of relational aggression as some forms of it are viewed as 'normative for adolescents' (Yoon, Barton \& Taiariol, 2004, p. 305). Dialogue about, and education to detect signs of relational aggression is thus essential. Teachers and school administrators with developed knowledge of relational aggression are more likely to identify, manage and intervene during these destructive episodes. Relational aggression is powerful enough to influence school climate; equally, school climate can shape it. Thus, in order for dropouts to reintegrate, the entire school climate or culture that condones relational aggression needs to be altered. Along with teacher/school administering education and training programmes on relational aggression, a conscious effort to target the context of the relationship and situation in which the relational and physical aggression occurs is required.

\section{Conclusions}

The study explored antisocial aspects in the social experience of dropouts re-enrolled in secondary school in South Africa. The aim was to demonstrate that antisocial behaviours targeted and defined the social experience of the dropouts who re-enrolled, and to highlight that the mere readmission of dropouts to school is not sufficient if they are to be successfully reintegrated into the school community. Evidence in the literature of the occurrence of re-enrolment of dropouts, and the urgency of building a sense of community in school in post-apartheid South Africa, prompted the empirical investigation.

The research found that the social experience of the participants was diverse and complex. The dropouts re-joined school but their experience was marked by social hostility, expressed in experiences of ostracism, isolation and rejection. In other words, as the dropouts returned to school, their drive for inclusion within the school community was aroused but frustrated by behaviours of social categorisation or differentiation and aggression by their schoolmates. These characterised the antisocial aspects that defined their social experiences. The relegation of these students to an out-group status was not only related to fear and self-esteem issues but also driven by particular motives which appear socially constructed and historically located within a matrix of intersecting modern and traditional forces. Relational and physical aggressions, which occurred in response to the out-group labelling, were major factors in the social categorisation of the re-enrolled dropouts. The reactions confirmed and substantiated previous studies.

Unless dropout reintegration is supported by a deliberate programme of intervention, aimed at getting them resettled into the school community, their school life will continue to be defined by prejudicial and hostile behaviours. The persistence of antisocial behaviours has several implications for the social and academic development of the re-enrolled dropouts such as interfering with key developmental tasks, social difficulties and 
maladjustments. The persistence of antisocial behaviours also has implications for the quality of the school climate that prevails in the school community. For dropouts to reintegrate, the entire school climate or culture that condones relational or physical aggression needs to be altered. This can start through teacher and school wide antisocial intervention strategies, as well as strategies targeting the victims and perpetrators of the intergroup hostility.

\section{References}

Beck, M., \& Malley, J. A. (1998). Pedagogy of belonging. Reclaiming Children and Youth, 7(3), 133-137.

Berliner, B., Barrat, V., Fong, A., \& Shirk, P. (2008). Re-enrolment of high school dropouts in a large, urban school district. Issues \& Answers Report, REL2008-No.056.

Bettencourt, B., Talley, A., Benjamin, A., \& Valentine, J. (2006). Personality and aggressive behaviour under provoking and neutral conditions: A meta-analytic review. Psychological Bulletin, 132(5), 751-777. http://dx.doi.org/10.1037/0033-2909.132.5.751

Bodenhausen, G. V., \& Peery, D. (2009). Social categorization and stereotyping in vivo: The VUCA challenge. Social and Personality Psychology Compass, 3, 1-19. http://dx.doi.org/10.1111/j.1751-9004.2009.00167.x

Borgia, L., \& Myers, J. (2010). Cyber safety and children's literature: A good match for creating classroom communities. Illinois Reading Council Journal, 38(3), 29-34.

Brewer, M. B. (1991). The social self: On being the same and different at the same time. Personality and Social Psychology Bulletin, 17, 475-482. http://dx.doi.org/10.1177/0146167291175001

Brewer, M. B. (1997). On the social origins of human nature. In C. McGarty, \& S. A. Haslam (Eds.), The message of social psychology (pp. 54-62). Oxford, UK: Blackwell.

Brewer, M. B. (1979). In-group bias in the minimal intergroup situation: A cognitive motivational analysis. Psychological Bulletin, 86, 307-324. http://dx.doi.org/10.1037/0033-2909.86.2.307

Briffa, M. (2010). Territoriality and aggression. Nature Education Knowledge, 1(8), 19.

Brown, B. (2010). Social hostility and the "dropout" syndrome: Leadership assisting youths' re-entry into school? Educational Review, 62(1), 53-67. http://dx.doi.org/10.1080/00131910903469577

Brown, B. (2013). "I was terrified of being labelled": The social experience of ex-dropouts re-enrolled in secondary school in South Africa. European Scientific Journal, 9(14), 157-175.

Bushnik, T., Barr-Telford, L., \& Bussière, P. (2002). In and Out of High School: First Results from the Second Cycle of the Youth in Transition Survey. Statistics Canada Catalogue 81-595-MIE- No.014. 2004.

Cant, M. A., Llop, J., \& Field, J. (2006). Individual variation in social aggression and the probability of inheritance: Theory and field test. American Naturalist, 167(6), 837-852. http://dx.doi.org/10.1086/503445

Carlson, B. (2002). Educación y Mercado de Trabajo en América Latina: ¿Qué nos dicen las cifras? CEPAL, Series Desarrollo Productivo, 14.

Chiamaka, I. (2010). Family murder. African languages and culture. Online. Retrieved from http://www.culture.chiamaka.com/igbo_suicide.html

Chuang, H. (1997). High school youths' dropout and reenrollment behavior. Economics of Education Review, 16(2), 171-186. http://dx.doi.org/10.1016/S0272-7757(96)00058-1

Coie, J. D., \& Dodge, K. A. (1998). Aggression and antisocial behavior. In W. Damon, \& N. Eisenberg (Eds.), Handbook of child psychology: Vol. 3. Social, emotional, and personality development (5th ed., pp. 779-862). New York: Wiley.

Corbin, J., \& Strauss, A. (1990). Basics of Qualitative Research: Grounded Theory, Procedures and Techniques. Newbury Park: Sage.

Crick, N. R., Casas, J. F., \& Nelson, D. A. (2002). Toward a more comprehensive understanding of peer maltreatment: Studies of relational victimization. Current Directions in Psychological Science, 11, 98-101. http://dx.doi.org/10.1111/1467-8721.00177

Dasgupta, N., DeSteno, D., \& Hunsinger, M. (2009). Fanning the flames of prejudice: The influence of specific incidental emotions on implicit prejudice. American Psychological Association, 9(4), 585-591.

De Wet, C. (2007). Educator's perceptions and observations of learner-on-learner violence-related behaviour. Africa Education Review, 4(2), 75-93. http://dx.doi.org/10.1080/18146620701652713 
Eckstein, Z., \& Wolpin, K. (1999). Why youth drop out of high school: The impact of preferences, opportunities and abilities. Econometrica, 67(6), 1295-1335. http://dx.doi.org/10.1111/1468-0262.00081

Erktin, E., Okcabol, R., \& Ural, O. (2010). Examining school related factors leading to dropout through children's conceptions and experiences: Development of a scale for attitudes towards elementary school. Australian Journal of Guidance and Counselling, 20(1), 109-118. http://dx.doi.org/10.1375/ajgc.20.1.109

Furman, G. (2002). Introduction. In G. Furman (Ed.), Creating a sense of community in public schools with diverse populations: Implications for leadership practice (pp. 1-19). Albany: State University of New York Press.

Goldstein, S. E., Young, A., \& Boyd, C. (2008). Relational aggression at school: Associations with school safety and social climate. Journal of Youth Adolescence, 37, 641-654. http://dx.doi.org/10.1007/s10964-007-9192-4

Grant, M., \& Hallman, K. (2006). Pregnant-related school dropout and prior school performance in South Africa. New York: Population Council.

Hawley, P., \& Vaughn, B. (2003). Aggression and adaptive function: The bright side to bad behaviour. Merrill-Palmer Quarterly, 49(3), 239-242. http://dx.doi.org/10.1353/mpq.2003.0012

Hogg, M. A., \& Vaughan, G. M. (2002). Social Psychology (3rd ed.). London: Prentice Hall.

Kachieng, M. (2004). Embracing myths and traditional beliefs in HIV/AIDS as a way of coping among African people living with the disease. Paper presented at the $15^{\text {th }}$ International Conference on AIDS. Bangkok, Thailand: 11-16 July.

Keenan, K., \& Shaw, D. (1997). Developmental and social influences on young girls' early problem behavior, Psychological Bulletin, 121, 97-113. http://dx.doi.org/10.1037/0033-2909.121.1.95

Keith, S., \& Martin, M. (2005). Cyber-bullying: Creating a culture of respect in a cyber-world. Reclaiming Children and Youth, 13(3), 224-228.

Knippenberg, V. E. A. (2002). Organizational Identification after a merger: A social identity perspective. British Journal of Social Psychology, 41, 233-252. http://dx.doi.org/10.1348/014466602760060228

Kuppens, S., Grietens, H., Onghena, P., Michiels, D., \& Subramanian, S. V. (2008). Individual and classroom variables associated with relational aggression in elementary school aged children: A multilevel analysis. Journal of School Psychology, 46, 639-660. http://dx.doi.org/10.1016/j.jsp.2008.06.005

Lahey, B. B., Schwab-Stone, M., Goodman, S. H., Rathouz, P., Miller, T. L., Canino, G., Bird, H., Jensen, P. S., \& Waldman, I. D. (1998). Age and gender differences in oppositional behaviour and conduct problems: A cross-sectional household study of middle childhood and adolescence. New York: SAGE.

Maharaj, P., Kaufman, C., \& Richter, L. (2000). Children's schooling in South Africa: transitions and tensions in households and communities, CSDS working paper. No. 30. Durban: University of Natal.

McLeod, S. A. (2012). Simply Psychology: Stereotypes. Retrieved from $\mathrm{http}: / /$ www.social\%20categorisation/Stereotypes.mht

McMahon, W. (1998). Conceptual Framework for the Analysis of the Social Benefits of Life-long Learning. Education Economics, 6(3), 309-346. http://dx.doi.org/10.1080/09645299800000022

Motala, S., Dieltiens, V., Carrim, N., Kgobe, P., Moyo, G., \& Rembe, S. (2007). Educational access in South Africa: Country analytic report. CREATE. Johannesburg: Wits EPU.

Peraita, C., \& Pastor, M. (2000). The primary school dropout in Spain: The influence of family background and labor market conditions. Education Economics, 8(2), 21-44. http://dx.doi.org/10.1080/096452900410721

Pooley, J. A., Breen, L., Pike, L. T., Cohen, L., \& Drew, N. M. (2008). Critiquing the school community: A qualitative study of children's conceptualizations of their school. International Journal of Qualitative Studies in Education, 21(2), 87-98. http://dx.doi.org/10.1080/09518390701207517

Raymond. M. (2008). High school dropouts returning to school. Catalogue no. 81-595-MNo. 055. Ottawa, Canada: Statistics Canada.

Reyna, R. (2011). State policies to reengage dropouts. NGA: Issue Brief. Online. Retrieved from http://www.nga.org/center

Rumberger, R. (2004). Why students drop out of school. In G. Orfield (Ed.), Dropouts in America: Confronting the graduation rate crisis. Cambridge, MA: Harvard University Press. 
Rumberger, R., \& Lamb, S. (1998). The early employment and further education experiences of high school dropouts: A comparative study of the United States and Australia. Paper prepared for the Organization for Economic Co-operation and Development (OECD).

Stejskal, J. (2010). Relational aggression and its effects on adolescents. Published master of Science in Counselling dissertation. Winona State University. Winona.

Sullivan, C. J. (2006). Early adolescent delinquency: Assessing the role of childhood problems, family environment, peer pressure. Youth Violence and Juvenile Justice, 4, 291-313. http://dx.doi.org/10.1177/1541204006292656

Tajfel, H. (1970). Experiments in intergroup discrimination. Scientific America, 223, 96-102. http://dx.doi.org/10.1038/scientificamerican1170-96

Tajfel, H. (1981). Human groups and social categories. Cambridge, UK: Cambridge Univ. Press.

Tajfel, H., \& Turner, J. C. (1986). The social identity theory of inter-group behaviour. In S. Worchel, \& L. W. Austin (Eds.), Psychology of Intergroup Relations. Chigago: Nelson-Hall.

Turner, J. C. (1982). Towards a cognitive redefinition of the social group. In H. Tajfel (Ed.), Social Identity and Intergroup Relations. Cambridge: Cambridge University Press.

UNESCO. (2010). Education for all Global Monitoring Report: Reaching the marginalised. Retrieved from http://www.unesco.org/fileadmin/MULTIMEDIA/HQ/ED/GMR/pdf/gmr2010-fs-ssa.pdf

Yoon, J., Barton, E., \& Taiariol, J. (2004). Relational aggression in middle school: Educational implications of developmental research. Journal of Early Adolescence, 24(3), 303-318. http://dx.doi.org/10.1177/0272431604265681

\section{Copyrights}

Copyright for this article is retained by the author(s), with first publication rights granted to the journal.

This is an open-access article distributed under the terms and conditions of the Creative Commons Attribution license (http://creativecommons.org/licenses/by/3.0/). 